\title{
Sustainable Design of a Thermosolar Electricity Generation Power Plant in Burkina Faso
}

\author{
Noelia Olmedo-Torre ${ }^{1}$, Lluc Canals Casals², Beatriz Amante García ${ }^{3}$ \\ 1, Graphic Engineering Department, EEBE, Universitat Politècnica de Catalunya (UPC) Barcelona-Tech, Spain. \\ E-mail: olmedo@ege.upc.edu \\ 2, Energy System Analytics research group, Energy and Power Electronics Department in Catalonia Institute for \\ Energy Research (IREC), Sant Adrià de Besòs, Spain \\ 3, Department of Project and Construction Engineering, ESEIAAT, Universitat Politècnica de Catalunya (UPC) \\ Barcelona-Tech, Spain
}

\begin{abstract}
Research towards renewable energy sources is of great relevance in the pursue of environmental impact reduction and to decrease the dependency on fossil fuels. In high solar irradiation locations, the use of Concentrating Solar Power technologies might be a good alternative in front of other power sources.

This study presents how multi-criteria methods such as the weighted technical analysis are useful to select the best heat transfer fluid to be used in a relatively small Concentration Solar Power plant in the Burkina Faso. To do so it analyzes three aspects, the technical performance of thermal fluids, their environmental impact and their price, giving them different weights to confer more or less relevance according to the idiosyncrasy of the region.

To do the technical analysis, this study simulates the heat gain and temperature increase of four heat transfer fluids while passing through a solar parabolic trough. The environmental impact factor is evaluated following the life cycle assessment methodology and the economic factor compares their price in the market.

Results show that Dowtherm A is the best choice for Burkina Faso and Marlotherm is the worst, but these results change considerably if the comparison is done in the USA, where the environmental factor gains relevance in contrast to the economic factor.
\end{abstract}

Keywords: Heat Transfer Fluid; Heat Collecting Elements; Parabolic Trough Systems; Concentrating Solar Power; Multi Criteria Selection; Life Cycle Assessment

\section{Introduction}

The International Energy Agency (Solar Paces, 2017) indicates that the primary energy demand will increase at a $1,5 \%$ rate until 2030, being fossil fuels such as natural gas, petrol and coal the principal power source representing an $80 \%$ of the total energy consumption. To confront this situation, the XXI International Conference on Climate Change agreed to reduce the global greenhouse gas (GHG) emissions to limit the global world warming below $2^{\circ} \mathrm{C}$ in 2100 (Paris Climate Change Conference, 2015). As the consumption of energy is essential for the production of goods, and electricity plays an important role in it, the reduction of GHG emissions might be achieved with the incorporation of renewable energy power sources.

Globally, planet Earth receives approximatively 170 PW of solar radiation in the higher limits of the atmosphere, where $30 \%$ is reflected to space and the rest is absorbed by seawater, earth surface and clouds. This radiation is more than enough to think of a developed society using technologies based on solar capture. It is said that $25 \%$ of energy necessities could be provided by Concentrating Solar Power (CSP) technologies by 2050 , which imply a reduction of 2.100 million tons of $\mathrm{CO}_{2}$ (Greenpeace International, 2009). Unfortunately, the higher costs of implementation, their relatively new technological advances and the low financial capability and resources of many countries with high potential to incorporate them, keep their entrance slow.

Burkina Faso is a good example. Having an $87 \%$ of the energy system based on fuel and a transmission and distribution grid with $14 \%$ losses (World Bank, 2014), its potential to reduce the GHG emissions in the generation 
of electricity is enormous. Additionally, there is still a huge amount of the population living in remote or dispersed villages without access to electricity. But access to electricity is not the only shortage its population has, water is also a scarce and valuable good. Burkina Faso has a particular climatology with a 3 months rainy season followed by a long period of drought that directly affects the quality and quantity of water. In fact, as it happens with electricity grid, access to treated and purified water is far from being warranted in relatively isolated settlements (Amante et al., 2016).

In views of this situation, the research group in the department of project and construction engineering in the UPC designed and build a pilot portable water treatment plant that can work either manually or electrically powered. This purification water plant uses the residual waste cake from the production of Moringa Oleifera oil as a coagulant/flocculants that captures and eliminates the suspended organic solids and disinfects water (LópezGrimau et al., 2013). Figure 1 presents an image of the actual prototype of the water treatment plant that has electric pumps and electro-valves to work in automated mode but it can also work manually with the manual pump and the manual activation of valves.

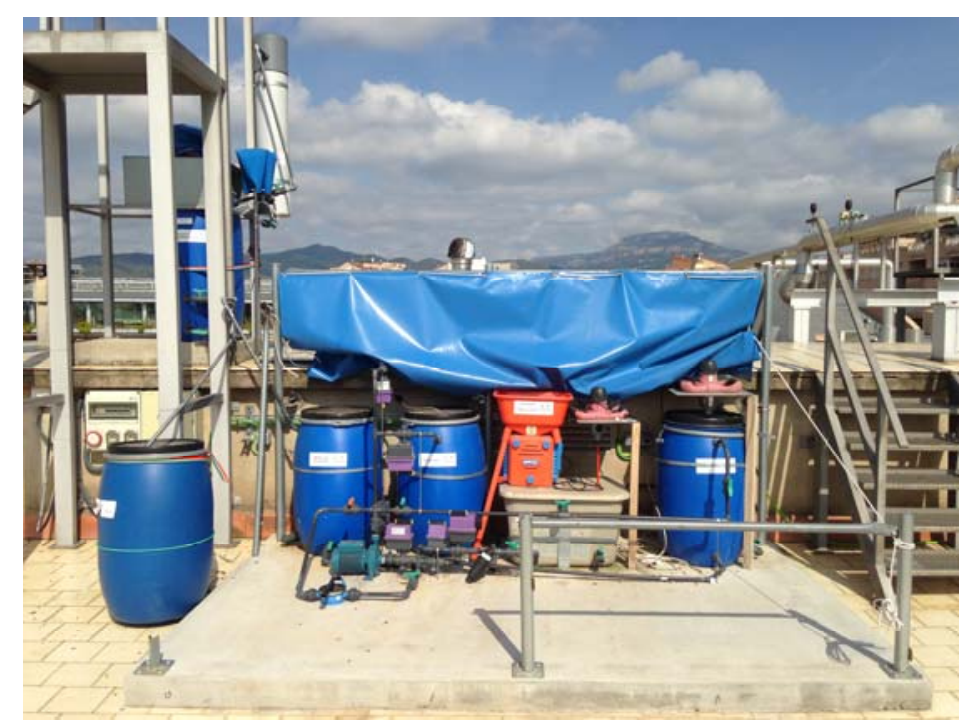

Figure 1: Prototype of the water purification plant.

This water treatment plant needs a source of power to run automatically. A previous study analyzed its energy consumption and indicated that renewable energy power sources, particularly those coming from the sun, where the most favorable alternative (Amante-García et al., 2017).

Within this framework, this study analyzes the possibility to consider CSP with Parabolic Trough Systems (PTS) to power this water treatment plant and the nearby villages, being CSP the most extended thermosolar technology with an implementation close to $90 \%$ against other similar alternatives (Deutsche Gesellschaft für Technische Zusammenarbeit, 2010). To achieve an effective introduction, CSP require, among other factors, high solar irradiation in relatively flat locations. In fact, two of the countries with higher installed CSP plants in the world are located in Africa (CSP World, 2015), (National Renewable Energy Laboratory, 2015).

Burkina Faso satisfies most of the requirements for the implementation of CSP plants, as the country has a flat orography with grasslands and small mountains (the top peak is $750 \mathrm{~m}$ high). Moreover, the solar irradiation indices are quite high in comparison to other places in the world (European Commission, 2017).

In this context, a cooperation project in one of the most impoverished countries in the world, as Burkina Faso is classified in the position 183 in the Human Development Index ranking (Human Development for Everyone, 2016), the price of components and materials acquisition to build and use the CSP plant is of great relevance.

Therefore, this study analyzes the technical, economic and environmental advantages to use a CSP plant in Burkina Faso to cover the electricity needs of rural settlements and a water purification plant.

The technical analysis is carried out simulating the behavior of four Heat Transfer Fluids (HTF) (Therminol VP1, Therminol 66, Dowtherm A y Marlotherm SH) through a $600 \mathrm{~m}$ solar parabolic trough (made of a number of solar collector modules) in a small CSP plant in the Burkina Faso. This study takes into consideration the seasons around the year and three solar irradiation incidence angles to determine their efficiency along the Heat 
Collecting Elements (HCE) using the software Solidworks Education Edition $2017^{\circledR}$. The environmental impact analysis is done following the life cycle assessment using the SIMAPRO software. The economic analysis compares the prices of these four HTF.

Finally, using multi-criteria tools, this study presents which of these four HTF obtains the best qualification to be used in a CSP plant in Burkina Faso.

\section{Methodology}

In the first place, this study presents the situation and characteristics of Burkina Faso's solar radiation. $T_{i}$ Error! No se encuentra el origen de la referencia.he annual global Direct Normal Irradiation (DNI) from various sites is higher than $1.800 \mathrm{kWh} / \mathrm{m} 2 /$ year, which seems to be adequate to install a CSP in the country.

The designed water purification plant has a peak power consumption below $5 \mathrm{~kW}$ and a total daily consumption of $11.178 \mathrm{kWh}$ (Amante-García et al., 2017) to treat 8.000 liters of water. Considering that local necessities might need more water, needing a bigger water treatment plant in consequence, and that in low income countries the energetic necessities of population are not guaranteed, the installed power plant should cover the energy demand of the treatment plant (or plants) and the nearby population needs.

Small CSP plants are capable to generate $1 \mathrm{MW}$ power with a solar field of around 3 or 4 hectares, like the pilot plant in Gurgaon, New Delhi (NREL, 2014) that produces hot $\left(350{ }^{\circ} \mathrm{C}\right)$ vapor at 42 bar to run a turbine generator that produces electricity with $600 \mathrm{~W} / \mathrm{m}^{2}$ of DNI and a solar field of $8.000 \mathrm{~m}^{2}$. However, fields may be bigger and capable to generate up to $360 \mathrm{MW}$, like the one in Pedro de Valdivia, Chile.

Nonetheless, the water treatment project was focused to cover the needs of small regions. In the pursue of a similar goal, this study considers that a 2-3 MW power plant is more than enough to cover the minimum necessities of the water treatment plant and other additional energy demand without substantially change the social situation and balances of a wide region. Similar CSP plants are spread around the world, such as the CSP plant in Saguaro (Southwest, EEUU) with a solar field of $10.340 \mathrm{~m}^{2}$ and a turbine capacity of 1,16 MW gross, the CSP in Holaniku (Keahole Point, Hawaii), that has a $3.500 \mathrm{~m}^{2}$ solar field to generate $2 \mathrm{MW}$ gross; the CSP in Massa Martana, Italy, that covers $3.398 \mathrm{~m}^{2}$ and has a turbine capacity of $0,35 \mathrm{MW}$ gross; the CSP in the city of Medicine Hat ISCC Project, Alberta, Canada, that has $5.248 \mathrm{~m}^{2}$ and generates 1,1 MW gross and the CSP in Cameo, Palisade, Colorado, (EEUU) that has a solar field of $6.540 \mathrm{~m}^{2}$ capable to generate $2 \mathrm{MW}$ gross.

CSP plants use lineal parabolic reflecting surface collectors to concentrate solar irradiation at the same focal point (Roldán Serrano M.I., 2017).

Figure 2 shows how HCE count on 5 different parts: The inner metallic tube (AISI 321), the external tube (glass), a metallic pleat and two parts in the edges that fix the pleat with the metallic tube (AISI 304). The average length of a HCE is $4,060 \mathrm{~m}$ with an internal diameter of $6,6 \mathrm{~cm}$ and external diameter of $12,5 \mathrm{~cm}$.

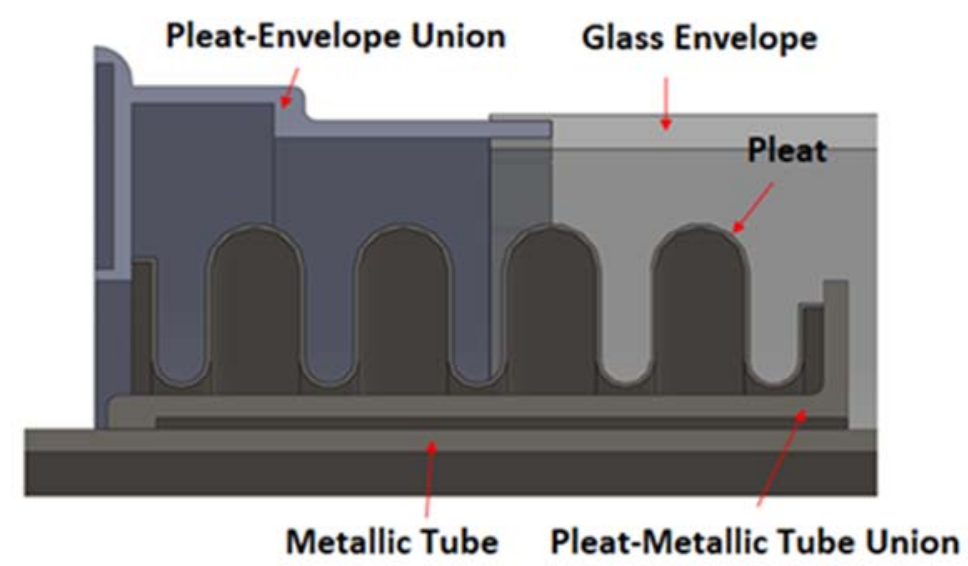

Figure 2: Inner design of the heat collecting elements in the simulation. 
The simulation is done using the software Solidworks Education Edition $2017^{\circledR}$ with the Flow Simulation complement taking into account the materials used in the design or the HCE. The HCE is a commercial SCHOTT PTR 70 used widely in the industry and research studies indicate that this HCE has high thermal efficiency and low heat losses in a CSP (Ouagued et al., 2013). The surface treatment of this HCE improved its heat losses considerably in comparison to the concurrence in 2008 (Forristall, R. 2003) (Burkholder and Kutscher, 2009) and it has been used in previous research works (Khanna et al., 2014). The simulation takes into account several previous works based on experimental setups and real applications that modeled the efficiency and validity of this software to evaluate heat gain in HCE (Dudley, 1994), (Moss and Brosseau, 2005), (Eck, 2005), (Eck, 2006), (Good, 2011), (Eck et al., 2010). In fact, Forristall highlights that the Engineering Equation Solver model could be used as a tool to improve the efficiency of new HCE (Forristall, R. 2003).

The materials (AISI 304, DIN 1.4541 and glass) of these elements are designed to respond positively to the specifications of the system. For the simulation, the inner surface of the metal tube has a roughness coefficient of $2,4 \mu \mathrm{m}$ and the heat transfer coefficient with the exterior is assumed to be $0 \mathrm{~W} / \mathrm{m}^{2} \cdot \mathrm{K}$ as done in other studies (Forristall, 2003) (Kelly and Kearney, 2006). Finally, the simulation incorporates the density of the fluid $\left(\mathrm{kg} / \mathrm{m}^{3}\right)$, its specific heat $(\mathrm{J} / \mathrm{kg} \cdot \mathrm{K})$, its thermal conductivity $(\mathrm{m} \cdot \mathrm{K})$ and dynamic viscosity $(\mathrm{Pa} \cdot \mathrm{s})$ reported in Table 1 .

There are basically four types of HTF: Water (economic but extremely essential in locations like Burkina Faso to be used for this purpose), oils (with good heating capacity that allows them to work up to $400{ }^{\circ} \mathrm{C}$ without a change of phase and at an affordable cost between 4 and $7 € / 1$ ), molten salts (with better heating capacity and temperature range but needing energy supply to maintain them above $150{ }^{\circ} \mathrm{C}$ to avoid solidification, increasing the installation and running costs); and liquid metals (having wider temperature ranges but with similar concerns in terms of solidification and costs) (Liang et al., 2015), (Roldán Serrano, 2017).

Similarly to synthetic oils, molten salts are widely used as HTF in CSP plants, having the advantage that their use is possible in solar fields and, at the same, in the storage circuit.

In spite of the efforts to reduce the costs in the storage system (Querol, 2012), of the efforts of providers to present new chemistries to increase efficiency and reduce costs (Peterseim et al., 2014), (Muñoz et al., 2015), (Kumar et al., 2015), (Barlev et al., 2011) and knowing that experiments are also considering other materials (as water or liquid metals), several authors consider that the use of molten salts in two tanks is preferable in commercial CSP plants (G. Kolb, 1998), (S. Relloso, 2009), (Burgaleta, 2011). Nonetheless, its costs is still very high (close to 30-50 US \$ / kWh), (IRENA, 2012) and even considering their temperature limitations, oils are still the HTF more extensively used in CSP (Vignarooban et al., 2015) (Roldán et al., 2013). Therefore, as costs are an important factor in the context of this study, oils are the chosen type of HTF to analyze.

Concerning oils, there are basically three type of oils: Mineral, Silicon and synthetic. All of them have similar conductivity $(0,1 \mathrm{~W} / \mathrm{m}-\mathrm{K})$ and working temperature values. This study compares the behavior of four oils (Therminol VP1, Therminol 66, Dowtherm A y Marlotherm SH) that are commercially used as HTF in CSP plants. The necessary characteristics for the simulation of these oils are detailed in ¡Error! No se encuentra el origen de la referencia., showing that Therminol VP1 y Dowtherm A are very similar.

Table 1: Characteristic and composition of the four HTF oils simulated (Eastman, 2015).

\begin{tabular}{|c|c|c|c|c|}
\hline & Therminol VP-1 & Therminol 66 & Dowtherm A & Marlotherm SH \\
\hline $\begin{array}{c}\text { Composition } \\
\begin{array}{c}\text { Eutectic mix } \\
\text { Diphenyl oxide } \\
73,5 \% \text { Biphenyl } \\
26,5 \%\end{array}\end{array}$ & $\begin{array}{c}\text { Terphenyl } \\
(100 \%)\end{array}$ & $\begin{array}{c}\text { Eutectic mix } \\
\text { Diphenyl oxide } \\
73,5 \% \text { Biphenyl } \\
26,5 \%\end{array}$ & $\begin{array}{c}\text { Ethylene Glycol } \\
95-98 \text { (\%) } \\
\text { Potassium } \\
\text { Hydroxide }(2 \%)\end{array}$ \\
\hline $\begin{array}{c}\text { Temperature working } \\
\text { range }\left[{ }^{\circ} \mathrm{C}\right]\end{array}$ & from 290 to 390 & $\begin{array}{c}\text { from } 240 \text { to } \\
340\end{array}$ & from 290 to 390 & from 240 to 340 \\
\hline $\begin{array}{c}\text { Viscosity at } 40{ }^{\circ} \mathrm{C} \\
(\mathrm{mm} 2 / \mathrm{s})\end{array}$ & 2,48 & 5,92 & 2,45 & 16,5 \\
\hline Density at $15^{\circ} \mathrm{C}(\mathrm{kg} / \mathrm{m} 3)$ & 1068 & 1064 & 1060 & 1040 \\
\hline Pressure at $\mathrm{max} . \mathrm{T} .(\mathrm{Bar})$ & 10,8 & 11,9 & 10,6 & 8,6 \\
\hline
\end{tabular}




\begin{tabular}{|c|c|c|c|c|}
\hline Price $(€ / 1)$ & 4,80 & 4,97 & 4,01 & 6,64 \\
\hline
\end{tabular}

The simulation of solar irradiation is carried out by projecting a heating source to the surface of the HCE according to the average irradiation $\left(\mathrm{kWh} / \mathrm{m}^{2}\right)$ in Burkina Faso. To do so, this study considers three different periods of solar irradiation: low irradiation period $(5,1 \mathrm{kWh}-5,5 \mathrm{kWh}$, July to September), high irradiation period $(6,2 \mathrm{kWh}-6,5 \mathrm{kWh}$, February-April) and medium irradiation period (rest of the year). Additionally, it considers three different solar incidence angles: $60^{\circ}$ from zenith (hours close to dusk and down), $30^{\circ}$ from zenith (morning or afternoon) and $0^{\circ}$ from zenith (central hours of the day).

This simulation considers the velocity of the HTF in the interior of the HCE that varies through the year according to solar irradiation and incidence angle as described in Table 2.

Table 2: Velocity of the fluid in the HCE in relation to ambient conditions.

\begin{tabular}{|c|c|c|c|c|c|c|c|c|c|}
\hline \multirow[b]{2}{*}{ Angle } & \multicolumn{3}{|c|}{ Low solar irradiation } & \multicolumn{3}{|c|}{ Medium solar irradiation } & \multicolumn{3}{|c|}{ High solar irradiation } \\
\hline & $60^{\circ}$ & $30^{\circ}$ & $\mathbf{0}^{\mathbf{o}}$ & $60^{\circ}$ & $30^{\circ}$ & $\mathbf{0}^{\mathbf{O}}$ & $60^{\circ}$ & $30^{\circ}$ & $\mathbf{0}^{\mathbf{o}}$ \\
\hline Velocity (m/s) & $\begin{array}{c}1,5 \text { to } \\
1,6\end{array}$ & $\begin{array}{l}2 \text { to } \\
2,2\end{array}$ & $\begin{array}{c}2,4 \text { to } \\
2,6\end{array}$ & $\begin{array}{c}1,5 \text { to } \\
1,6\end{array}$ & 2,7 to 3 & $\begin{array}{c}3,2 \text { to } \\
3,6\end{array}$ & $\begin{array}{c}1,5 \text { to } \\
1,6\end{array}$ & $\begin{array}{c}3,4 \text { to } \\
3,8\end{array}$ & $\begin{array}{c}4 \text { to } \\
4,5\end{array}$ \\
\hline $\begin{array}{l}\text { Temperature } \\
\text { Average high } \\
\text { and low }\left({ }^{\circ} \mathrm{C}\right)\end{array}$ & \multicolumn{3}{|c|}{$23,8^{\circ}$ to $32,2^{\circ}$} & \multicolumn{3}{|c|}{$25,3^{\circ}$ to $35,1^{\circ}$} & \multicolumn{3}{|c|}{$27^{\circ}$ to $39,5^{\circ}$} \\
\hline
\end{tabular}

The environmental analysis considers these same four HTF oils. The study uses the software SIMAPRO to evaluate the environmental impact of each oil using the Ecoinvent database and the ReCiPE World E/A methodology to calculate it.

The boundary conditions of this analysis consider the extraction of raw materials, its transportation to the fabrication plant, the necessary energy to produce or obtain essential compounds or the proper oil and the transportation of HTF to Burkina Faso.

Figure 3 presents the steps and considerations of Therminol VP1 as an example. The environmental impact of the use phase is not considered in this analysis because it is assumed to be similar in all cases and, additionally, the efficiency of the fluid is evaluated in the technical analysis and it would have a double effect in the ulterior multi-criteria analysis.

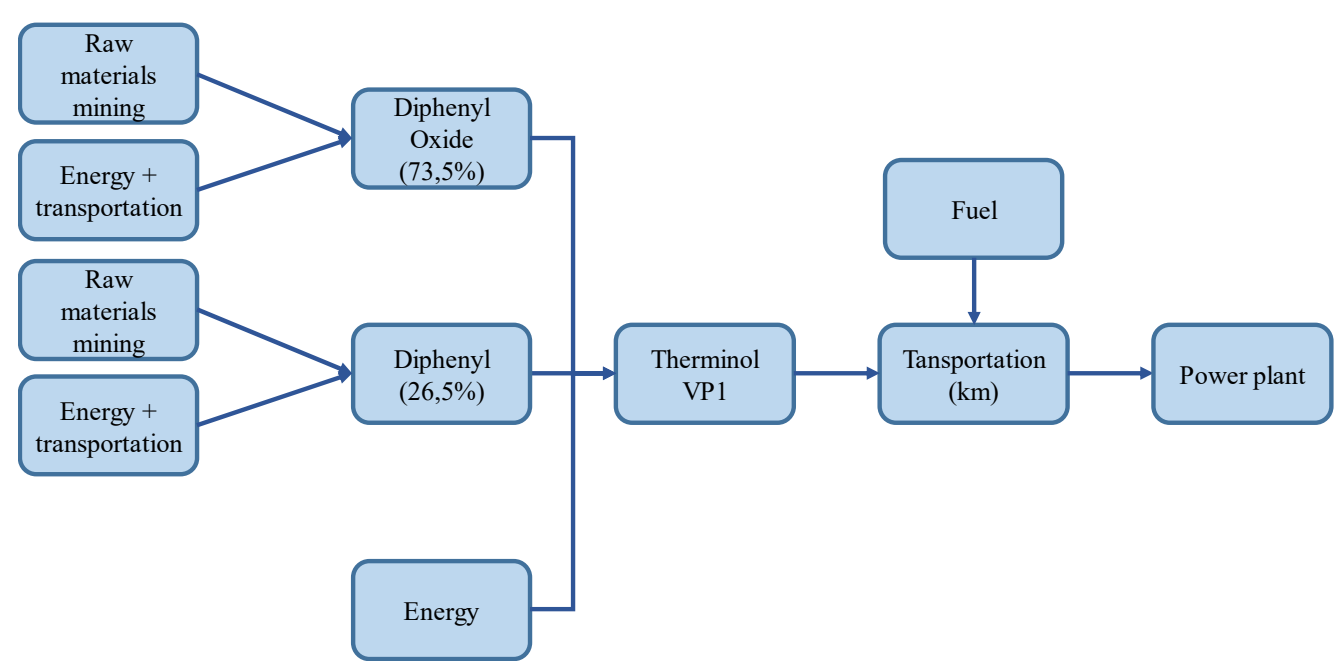

Figure 3: Example of the boundary conditions of the Therminol VP1 
The functional unit used in this study is 11 of oil and the specific consideration for the environmental analysis of each oil is summarized in Table 3 ¡Error! No se encuentra el origen de la referencia..

Table 3: Considerations for the Life Cycle Assessment inventory.

\begin{tabular}{|c|c|c|c|c|}
\hline Characteristic & Therminol VP1 & Therminol 66 & Dowtherm A & Marlotherm SH \\
\hline Diphenyl Oxide & $73.5 \%$ & - & $73 \%$ & - \\
\hline Biphenyl & $26.5 \%$ & - & $27 \%$ & - \\
\hline Terphenyl & & $100 \%$ & - & - \\
\hline Ethylene Glycol & - & - & - & $98 \%$ \\
\hline Potassium Hydroxide & - & - & - & $2 \%$ \\
\hline Transportation: & \multicolumn{2}{|c|}{$\mathrm{km}$} & $\mathrm{km}$ & $\mathrm{km}$ \\
\hline Truck to port & \multicolumn{2}{|c|}{1200} & negligible & negligible \\
\hline Ship & \multicolumn{2}{|c|}{9500} & 7700 & 8000 \\
\hline Truck to destination & \multicolumn{2}{|c|}{1500} & 1500 & 1500 \\
\hline
\end{tabular}

Unfortunately not all the compounds of these four HTF from Table 3, such as Biphenyl and Terphenyl, are available as such in Ecoinvent libraries. Nonetheless, Biphenyl can be obtained as a derived product from the production of Benzene in a relation of $1 \mathrm{~kg}$ of Biphenyl for every $100 \mathrm{~kg}$ of Benzene with a purity close to 93-97 $\%$ or following a process of thermal dehydrocondensation of Benzene, that is, heating Benzene electrically in a multi-tube reactor to obtain higher purity Biphenyl (99,5\%) that improves the durability and efficiency of oils in thermo-solar applications (C. Lang, 2015). Following this latter option, Benzene is decomposed obtaining $80 \%$ of Biphenyl and $0.7 \%$ of Terphenyl among other compounds (Griesbaum et al, 2015), (Nostrand's, 2013). As Benzene is available in the Ecoinvent database, the proportional amount of it is used in the calculations depending on the need of Therphenyl and Biphenyl for each oil. In addition, the study considers the amount of electricity needed in the oil production processes, whose environmental impact would differ according to the electricity mix of the country where each oil is manufactured.

To evaluate the impact of transportation from the oil manufacture plant to Burkina Faso, this study considers three transportation steps: the distance by road from the manufacture plant to port; the distance by ship from the port to Brukina Faso's closest big African port (Abidjan); and the distance from this port by road to Burkina Faso $(1500 \mathrm{~km})$. This latter transportation step is equal for all HTFs. For more details, Therminol oils (VP1 and 66), which are fabricated in Kingsport (Tennesse, USA), are sent in a 25 ton truck to South Lousiana port (defined as lorry 16-32t, EURO4/RER U in the Ecoinvent database), the biggest international port in USA, Then they are shipped to Abidjan (Côte d'Ivoire) using a transoceanic ship. Finally, a 7,5 ton truck (lorry 3.5-7.5t, EURO3/RER U) transports HTF to Burkina Faso. Notice the differences in the Euro-X qualification of trucks that refer to European standards of pollution from vehicles. The transportation in Burkina has a lower qualification due to the softer regulatory framework of the country in environmental issues. A similar procedure is used for the other two HTF, considering that Dowtherm A is produced in Rotterdam (Netherlands) and Marlotherm SH in Hamburg (Germany). In these cases, both cities count on important maritime ports and the first road transportation step can be neglected due to the proximity between the manufacture plant and port. Detailed information about distances is available in Table 3.

The price of oils, already presented in Table 1, is the last of the factors taken into account for the selection of the most appropriate oil to be used in a CSP plant using a multi-criteria methodology based in a Weighted Technical Analysis (WTA). First, the WTA puts all the factors at the same scale following equation (1), that is, for each factor the best qualified oil receives a Technical Value (TV) of 1, while the worse obtains a 0 . Then, WTA gives different weights to each of the factors that intervenes in the selection giving more relevance to some of the factors in relation to the others according to the reality of the region analyzed, as summarized in Table 4 . 


$$
\mathrm{TV}=(\text { Value }-\mathrm{Min}) /(\text { Max-Min })
$$

In order to facilitate an extension of this study including molten salts in future research, this study gives a value of 4 to weight the technical efficiency factor as their temperature working range is lesser than half of what molten salts offer (Vignarooban et al., 2015). Moreover, the efficiency factor considers the Weighted Mean (WM) of the resulting power from a solar parabolic trough (PT) in relation to the solar incidence angle and the solar irradiation according to the ratio of time that the power plant works in each climate condition described in Table 4 and following equations (2), (3), (4) and (5), where HIPT, MIPT and LIPT mean High, Medium and Low Irradiation Power through the PT.

$$
\begin{aligned}
& \mathrm{HIPT}=\left(\mathrm{HIPT}^{\circ} \cdot 0,14+\mathrm{HIPT}^{\circ} 0^{\circ} \cdot 0,47+\mathrm{HIPT}^{\circ} 0^{\circ} \cdot 0,39\right) \\
& \mathrm{MIPT}=\left(\mathrm{HIPT}^{\circ} \cdot 0,1+\mathrm{HIPT}^{\circ} 0^{\circ} \cdot 0,5+\mathrm{HIPT}^{\circ} \cdot 0,4\right) \\
& \text { LIPT }=\left(\mathrm{HIPT}^{\circ} \cdot 0,16+\mathrm{HIPT}^{\circ} 0^{\circ} \cdot 0,46+\mathrm{HIPT} 60^{\circ} \cdot 0,38\right) \\
& \mathrm{WM}=(\mathrm{HIPT} \cdot 0,25)+(\mathrm{MIPT} \cdot 0,5)+(\mathrm{LIPT} \cdot 0,25)
\end{aligned}
$$

The weight for the environmental impact factor is calculated according to the ecological footprint (EF) of the country. Although climate change is a global problem, there are some countries with higher EF than others and it would be unfair to force countries with lesser environmental impact to do the same efforts than those with higher responsibilities on climate change. According to the Global Footprint Network, Burkina Faso is ranked 146 with an ecological footprint of 1,19 that is $86,47 \%$ lower than the EF corresponding to Austria, which is estimated to be 8,8 (Global Footprint Network, 2013). In consequence, the environmental weight assigned to Burkina is 1,3, as presented in Table 4. Notice that this weight factor should be corrected or adapted following this same methodology if the solar power plant should be installed in any other country.

Following this same fairness principle, the weight for the economic factor is calculated using the Human Development Index (HDI). HDI is used in this study in front of the Gross Domestic Product (GDP) index due to the wider consideration of development that the HDI has. In fact, GDP considers only wealth, leaving aspects such as health or education aside, while HDI considers them in its formulation. In the introduction we have already mentioned that Burkina is one of the more impoverished countries in the world and its HDI is 0,4 in a scale of 1 , being Norway the country with higher HDI $(0,94)$. In correspondence, the economic factor is clearly the most relevant in this case and its weight corresponds to 9, as presented in Table 4. Again, this parameter is used to

\begin{tabular}{|c|c|c|c|c|c|c|c|c|c|c|}
\hline Factor & \multicolumn{9}{|c|}{ Efficiency Weighted Mean } & WTA \\
\hline \multirow{4}{*}{$\begin{array}{l}\text { Power PT } \\
\text { Efficiency }\end{array}$} & \multirow{2}{*}{\multicolumn{3}{|c|}{$\frac{\text { High Irradiation }}{25 \%(3 \text { months })}$}} & \multirow{2}{*}{\multicolumn{3}{|c|}{$\frac{\text { Medium Irradiation }}{50 \%(6 \text { months })}$}} & \multirow{2}{*}{\multicolumn{3}{|c|}{$\begin{array}{l}\text { Low Irradiation } \\
25 \% \text { (3 months })\end{array}$}} & \multirow{4}{*}{4} \\
\hline & & & & & & & & & & \\
\hline & $\mathbf{0}^{\mathbf{o}}$ & $30^{\circ}$ & $60^{\circ}$ & $\mathbf{0}^{\circ}$ & $30^{\circ}$ & $60^{\circ}$ & $\mathbf{0}^{\mathbf{O}}$ & $30^{\circ}$ & $60^{\circ}$ & \\
\hline & $14 \%$ & $47 \%$ & $39 \%$ & $10 \%$ & $50 \%$ & $40 \%$ & $16 \%$ & $46 \%$ & $38 \%$ & \\
\hline Environmental & & & & & & & & & & 1,3 \\
\hline Economic & & & & & & & & & & 9 \\
\hline
\end{tabular}
highlight the relevance of the cost of materials in impoverished countries in comparison to other countries having higher incomes. In consequence, this weighting value should be adapted if future studies consider other countries. In the results section, an example of how this weighting affects the final choice is presented.

Table 4: Weights given to efficiency and for the WTA.

\section{Results and Discussion}

This section begins with the analysis of the efficiency of oils by observing the heat gain and the temperature increase results of the simulation at different seasons of the year and in different hours. Figure 4 shows how the temperature of HTF increases storing heat through the PTS in three of the cases analyzed, the one that gives best 
results that corresponds to the season with high irradiation indices at zenith hours (Figure 4 a and b), a middle situation (Figure $4 \mathrm{c}$ and $\mathrm{d}$ ) and the worst case during low irradiation season at dusk or down (Figure $4 \mathrm{e}$ and $\mathrm{f}$ ).

Therminol VP1 and Dowtherm A perform better than the other two HTF (Therminol 66 and Marlotherm), having higher heat gain and temperature increase while passing through the installation. It seems reasonable that oils having higher heat gain are the ones with higher temperature increase and, in consequence, they have better efficiency.

It is no surprise that Therminol VP1 and Dowtherm A show a similar behavior, as their main compounds are the same. The slight higher temperature increase from Dowtherm A is caused, basically, due to its higher specific heat.

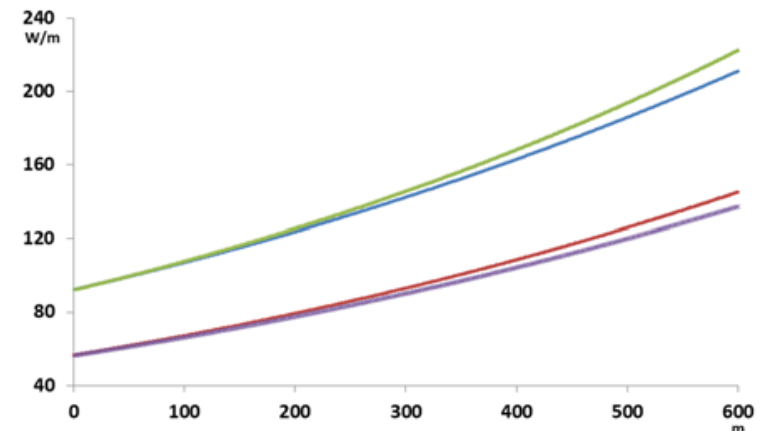

a) Heat gain / High solar irradiation $/ 0^{\circ}$

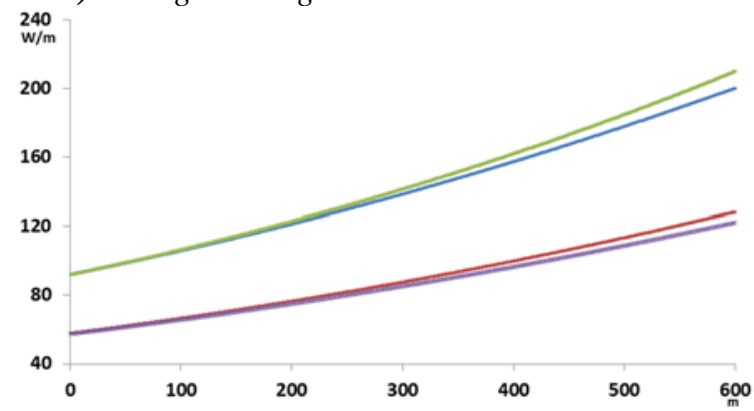

c) Heat gain / medium solar irradiation / $30^{\circ}$

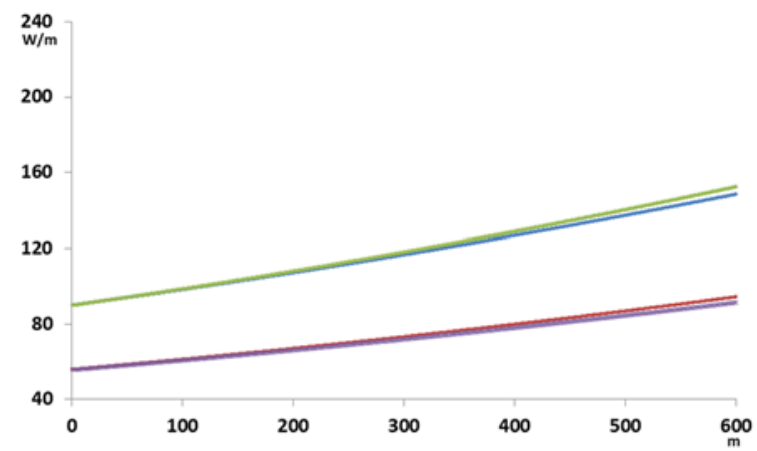

e) Heat gain / low solar irradiation $/ 60^{\circ}$

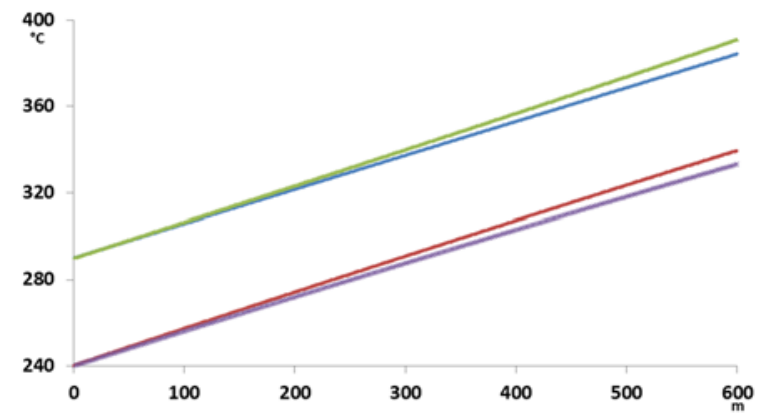

b) Temperature HTF / High solar irradiation / $0^{\circ}$

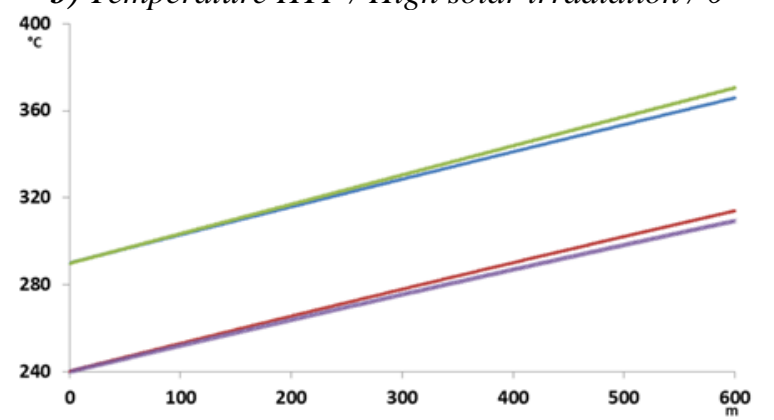

d) Temperature HTF /Medium solar irradiation $/ 30^{\circ}$

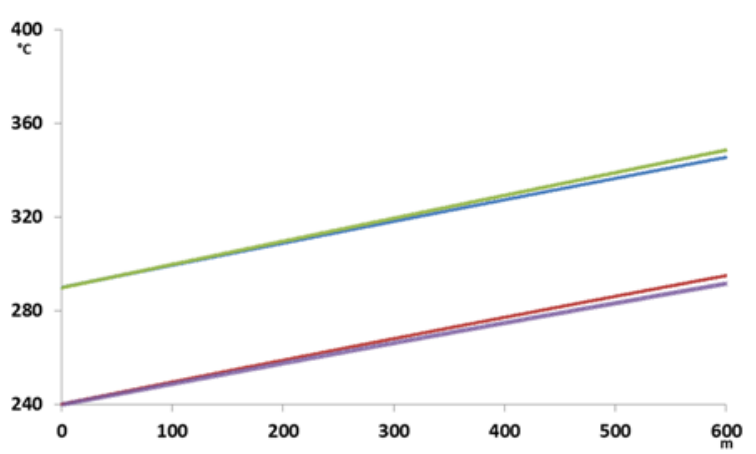

f) Temperature HTF / Low solar irradiation / $60^{\circ}$

Therminol VP1 Therminol 66

Dowtherm A Marlotherm SH

Figure 4: Oils' heat gain and temperature increase through the PTS

Due to the particular conditions of Burkina Faso, heat gain and temperature increase do not show huge differences between high (Figure $4 \mathrm{a}$ and $\mathrm{b}$ ) and medium (Figure $4 \mathrm{c}$ and $\mathrm{d}$ ) irradiation seasons.

On the contrary, during the low irradiation season at $60^{\circ}$ incidence angle (Figure 4 e and $\mathrm{f}$ ), there are clear changes in the performance of the HTF. These differences are basically influenced by the solar incidence angle rather than by the lower irradiation season as evidenced in Table 4. 
In fact, the difference in heat gain at the end of the PTS for Marlotherm between the worst case (low irradiation at $60^{\circ}$ ) and the best case (high irradiation at $0^{\circ}$ ) is only a $9 \%$ while for Dowtherm A this difference increases up to a $43 \%$.

In all the cases we notice a significant difference between Therminol VP1 and Dowherm A in comparison to Marlotherm SH and Therminol 66. These latter fluids have lower heat gain and offer a sensitively poorer behavior due to the fact that their working temperature range goes from $240^{\circ} \mathrm{C}$ to $340^{\circ} \mathrm{C}$, which is their main drawback in comparison to synthetic oils such as Therminol VP1 and Dowtherm A that are expected to work between 290 and $390{ }^{\circ} \mathrm{C}$. In fact, the initial temperature of these HTF is different in the simulation in order to follow the optimal working conditions defined by manufacturers.

For the particular case of Therminol VP1, its density and viscosity decrease faster with temperature increase and the total flow does not suffer any appreciable variation. Figure 5 shows the distribution of temperatures in a $\mathrm{HCE}$ and how higher temperature values are located near the tube walls, where heat collection by convection takes place.

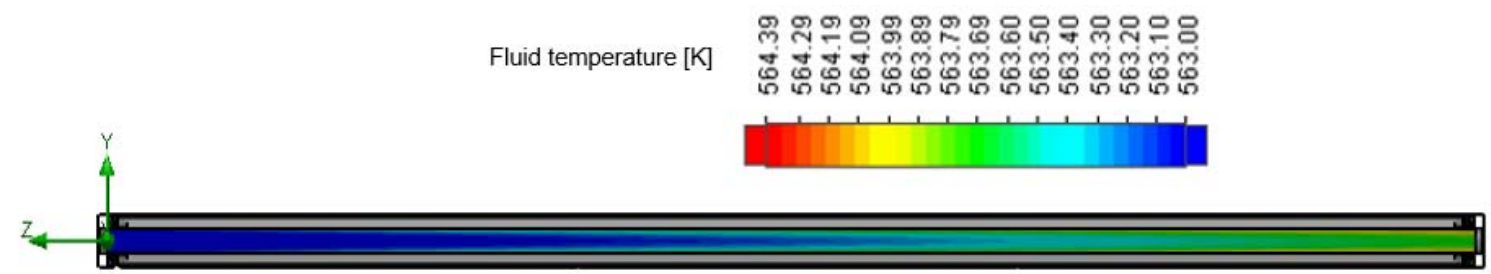

Figure 5: Temperature distribution for Therminol VP1 through a PTS.

Table 4 shows the average power obtained in a PTS for the analyzed HTF in relation to the solar irradiation and incidence angle. It clearly shows how the difference caused by irradiation is lower than the difference caused by the incidence angle. In fact, power in the PTS during low irradiation periods is only a $60 \%$ of what PTS offers during high irradiation periods, while the impact of the incidence angle represents a $40 \%$ decrease. The sum of both effects makes that the scenario with worse irradiation (low irradiation at $60^{\circ}$ ) provides a $24 \%$ of the power obtained in the best case (high irradiation at zenith). Moreover, Table 4 confirms that Therminol VP1 and Dowtherm A are the oils that perform better in these situations. These results are consistent, knowing that both oils have similar composition.

Differences in thermal gain and working temperature for these type of oils are not that important in a 2-3MW power plant, as they are all designed to work in similar weather conditions offering similar results. However, there are other factors, such as price and environmental impact that may be more relevant.

Table 4: Power of the PTS of the analyzed HTF in relation to solar irradiation and incidence angle.

\begin{tabular}{|l|c|c|c|c|c|c|c|c|c|}
\hline \multicolumn{1}{|c|}{ HTF } & \multicolumn{10}{c|}{ Power HTF in PTS (MW) } \\
\hline Irradiation & \multicolumn{2}{|c|}{ Low Radiation } & \multicolumn{2}{c|}{ Middle Radiation } & \multicolumn{3}{c|}{ High Radiation } \\
\hline Angle Incidence & $\mathbf{0}^{\circ}$ & $\mathbf{3 0}^{\circ}$ & $\mathbf{6 0}^{\circ}$ & $\mathbf{0}^{\circ}$ & $\mathbf{3 0}^{\circ}$ & $\mathbf{6 0}^{\circ}$ & $\mathbf{0}^{\circ}$ & $\mathbf{3 0}^{\circ}$ & $\mathbf{6 0}^{\circ}$ \\
\hline Dowtherm A & 1,637 & 1,374 & 0,691 & 2,201 & 1,850 & 0,849 & 2,766 & 2,327 & 0,964 \\
\hline Therminol VP1 & 1,635 & 1,372 & 0,685 & 2,199 & 1,848 & 0,841 & 2,763 & 2,324 & 0,962 \\
\hline Therminol 66 & 1,593 & 1,333 & 0,677 & 2,155 & 1,806 & 0,837 & 2,715 & 2,279 & 0,926 \\
\hline Marlotherm SH & 1,590 & 1,329 & 0,675 & 2,151 & 1,803 & 0,833 & 2,711 & 2,276 & 0,923 \\
\hline
\end{tabular}

From and environmental perspective, the results from the life cycle assessment using SIMAPRO presented in Figure 6 show that Therminol 66, composed basically by therphenyl, is the oil that entails higher environmental impact, being 6,71 times higher than Malortherm that is the oil with lesser environmental impact the only oil that does not count on phenyls in its composition. Additionally, Therminol 66's environmental impact is 3,5 times higher than the impact of Therminol VP1 and Dowtherm A. Again, these two oils, having a similar composition, do also present equivalent environmental impact results. 
Figure 6 also shows that the environmental impact is caused mainly by the categories of Climate change Human Health (maroon), Human Toxicity (red), Particulate matter formation (brown), Climate change ecosystems (orange) and Fuel Depletion (yellow), while the rest of categories (marked in a degradation of blues) are almost irrelevant in comparison to these 5.

To ease the evaluation, Figure 7 shows the results grouped in three categories affecting Human Health, Ecosystems or Resources for the four oils. This distribution shows how the environmental impact to produce and transport these oils affect Human Health and Resource Depletion (basically fossil). These results could be explained by the fact that phenyl compounds are obtained from petroleum and because transportation also consumes fossil fuels.

We should mention that electricity consumption and transportation do have a secondary role in the environmental impact analysis, as the main contribution comes from the production of oils and their compounds. In fact, analyzing the environmental impact of Therminol VP1, the contribution of electricity to the overall impact represents only a $1 \%$ while transportation from USA to Burkina Faso is responsible of a $13 \%$ of the total environmental impact ( $71 \%$ of which corresponds to transportation by truck in Africa).

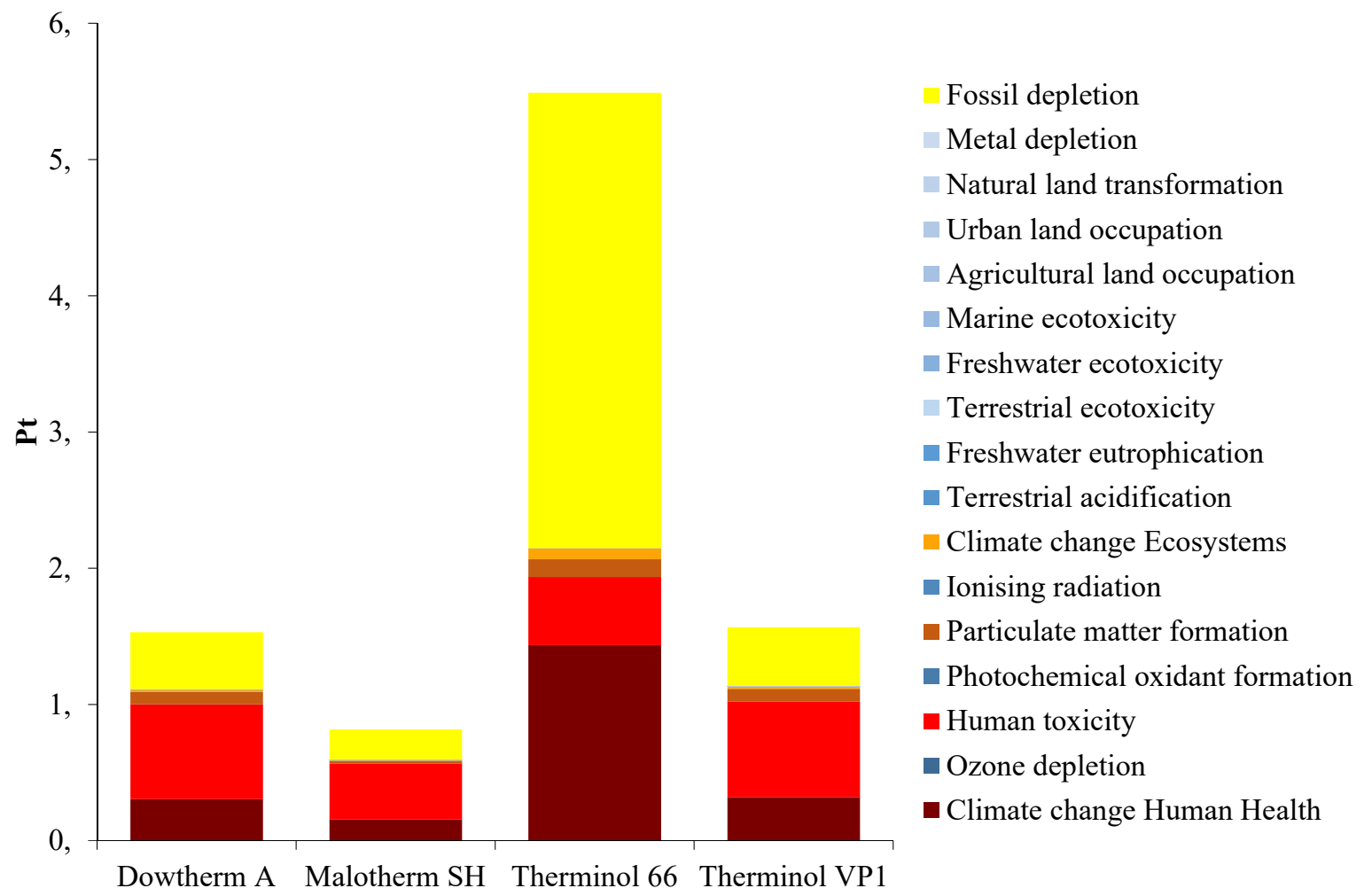

Figure 6: Normalized environmental impact of the four HTF oils. 


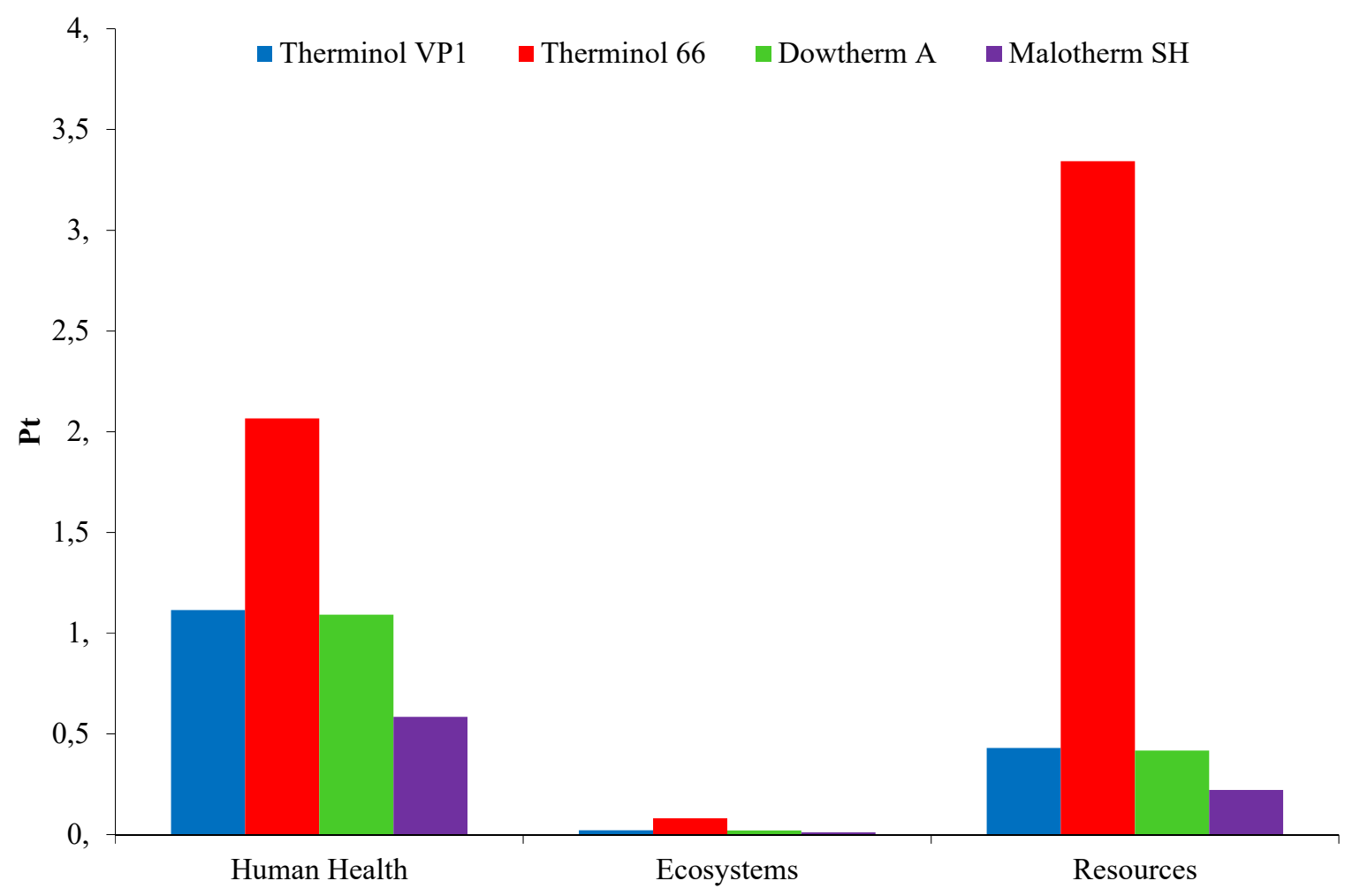

Figure 7: Comparison of the normalized environmental impact grouped in categories affecting Human Health, Ecosystems and Resources.

Finally, the study presents the WTA that, taking advantage of the partial results from the technical and environmental analysis, presents the oil that better satisfies the particular requirements of Burkina Faso. To do so, the WTA considers three factors, previously described in the methodology: Efficiency, environmental impact and price.

In views of Table 5 it seems that Dowtherm A is the best option to use in Burkina Faso. In fact, it is the oil that performs better and it is cheaper than the rest of the oils analyzed and, although it is not the best solution from and environmental point of view, price is far too relevant in Burkina Faso, giving Dowtherm A the highest qualification. Moreover, Marlotherm, that is the HTF having lower environmental impact, obtains the lowest qualification and it should be totally discarded basically because of its higher cost.

Nonetheless, these results are only valid for this region. If this same analysis was made in, for example, USA, the weight factor related to the environmental impact would increase from the 1,3 shown in Table 4 to a value of 6,5 due to the higher ecological footprint of this country, which is considered to be of 8,59 . The economic weight would change in the opposite direction. If this is the most important criteria for Burkina Faso, it is almost negligible for countries that count on high HDI such as USA, whose HDI is 0,92 which corresponding economic weight value would be 0,8 . Under these alternative circumstances, the use of Therminol VP1 or Dowtherm A would be almost equally acceptable, as the WTA for Therminol VP1 increases almost 10 points and for Dowtherm A it decreases 8 points. What is more relevant is that the qualifications for Marlotherm SH and Therminol 66 switches drastically, as the environmental impact are considered the best and worst respectively in this study and this factor is the most relevant in high polluting countries such as USA.

Table 5: Multicriteria results applying the Weigtened Technical Analysis in Burkina Faso.

\begin{tabular}{|l|c|c|c|c|}
\hline Factor & Therminol VP1 & Therminol 66 & Dowtherm A & Marlotherm SH \\
\hline Technical & 0,902 & 0,087 & $\mathbf{1}$ & 0 \\
\hline Environmental & 0,840 & 0 & 0,848 & $\mathbf{1}$ \\
\hline Economical & 0,700 & 0,635 & $\mathbf{1}$ & 0 \\
\hline WTA & $\mathbf{7 6 , 9 \%}$ & $\mathbf{4 2 , 4} \%$ & $\mathbf{9 8 , 6} \%$ & $\mathbf{9 , 1} \%$ \\
\hline
\end{tabular}


These results indicate that, although it is recommended to use the best qualified of HTF, as they all behave similarly, it is most recommendable to thoroughly select a good location to install the CSP plant as it would reduce the dimension and costs of the solar field. Additionally, the cost to acquire these oils seems to be of major importance and the closeness of dealers might be important too.

Moreover, other HTF with higher working temperature range, such as molten salts, could be included into the multi-criteria analysis in high income countries where investment costs are less troublesome once they overcome the corrosive effect they have on metallic alloys and the use of nitrates/nitrites. In fact, recent studies propose molten salts based on carbonate chloride (Vignarooban et al., 2015).

\section{Conclusions}

Concentrating Solar Power technology is adequate for the climate and geographical reality of Burkina Faso and its environmental impact is lower than using other alternatives. However there are several sociological barriers that should be taken into consideration when projecting the installation of such technologies in impoverished countries or regions. In fact, although their contribution in the world's energy market is still limited, CSP are called to play an important role in the future to come, as installation price may substantially drop and because the design of PTS and the use of more efficient HTF may increase their performance and profitability.

The technical analysis showed that Therminol VP1 and Dowtherm A are the ones performing better because of the higher working temperature range, fewer heat and pressure losses and their lower viscosity. Moreover, these two oils are cheaper than the others and cost is of major relevance in impoverished countries.

From an environmental point of view, Marlotherm oil, being the only oil analyzed that does not come from hydrocarbon, is the one showing lesser environmental impact.

Although there are no major differences from a technical performance perspective, this study shows how multi-criteria methodologies are useful to help decision making.

\section{References}

Amante-García, B., López-Grimau, V., Canals Casals, L., 2017. LCA of different energy sources for a water purification plant in Burkina Fasso. Desalin. WATER Treat. 76, 375-381. doi:10.5004/dwt.2017.20462

Amante, B., López-Grimau, V., Smith, T., 2016. Valuation of oil extraction residue from Moringa oleifera seeds for water purification in Burkina Faso. Desalin. Water Treat. 57, 2743-2749. doi:10.1080/19443994.2015.1047408

Barlev, D., Vidu, R., Stroeve, P., 2011. Innovation in concentrated solar power. Sol. Energy Mater. Sol. Cells 95, 27032725. doi:10.1016/j.solmat.2011.05.020

Burgaleta, J., 2011. Gemasolar: the first tower thermosolar commercial plant with molten salt storage, in: SolarPACES, Conference, Granada.

Burkholder, F., Kutscher, C.F., 2009. Heat loss testing of Schott's 2008 PTR70 parabolic trough receiver. NREL Tech. Rep. 58.

C. Lang, B.L., 2015. HTF life time analysis of Diphenyl oxide and Biphenyl. Energy Procedia.

CSP World, 2015. CSP World Map. http://cspworld.org

Deutsche Gesellschaft für Technische Zusammenarbeit, 2010. Renewable Energy Policy Network for the 21st Century.

Dudley, V.E. et al., 1994. SEGS LS2 solar collector-test results.

Eastman, 2015. Selection guide for heat transfer fluids. http://emnmktassets.blob.core.windows.net/therminol/Therminol_Product_Selection_Guide_TF01A.pdf

Eck, M., 2006. Development of Receivers for the DSG Process in SolarPACES, Seville.

Eck, M. and W.-D.S., 2005. Modelling and Design of Direct Solar Steam Generating Collector Fields. J. Sol. Energy Eng.

Eck, M., Feldhoff, J.F., Uhlig, R., 2010. Thermal Modelling and Simulation of Parabolic Trough Receiver Tubes. ASME 2010 4th Int. Conf. Energy Sustain. Vol. 2 659-666. doi:10.1115/ES2010-90402

European Commission, 2017. Institute for Energy and Transport (IET). Interact. maps Animat. 
Forristall, R., 2003. Heat Transfer Analysis and Modeling of a Parabolic Trough Solar Receiver Implemented in Engineering Equation Solver 164. doi:NREL/TP-550-34169

G. Kolb, 1998. Economic evaluation of solar only and hybrid power towers using molten salt technology. Sol. Energy 62, $51-61$.

Global Footprint Network, 2013. Sustainable development. URL http://data.footprintnetwork.org/. (accessed 10.31.17).

Good, P., 2011. Heat transfer modeling of a solar parabolic trough receiver by direct simulation monte Carlo method 104.

Greenpeace International, S.P. and S., 2009. Concentrating Solar Power Global Outlook 09. Power 88.

Griesbaum et al, 2015. Hydrocarbons. Ullmann's Encycl. Ind. Chem.

Human Development for Everyone, 2016. Human Development Report.

IRENA, 2012. Renewable Energy Technologies Cost Analysis Series: Concentrating Solar Power. Compr. Renew. Energy 3 , 595-636. doi:10.1016/B978-0-08-087872-0.00319-X

Kelly, B., Kearney, D., 2006. Parabolic Trough Solar System Piping Model Final Report Parabolic Trough Solar System Piping Model Final Report. NREL Subcontract Rep.

Khanna, S., Singh, S., Kedare, S.B., 2014. Effect of angle of incidence of sun rays on the bending of absorber tube of solar parabolic trough concentrator. Energy Procedia 48, 123-129. doi:10.1016/j.egypro.2014.02.015

Kumar, V., Shrivastava, R.L., Untawale, S.P., 2015. Fresnel lens: A promising alternative of reflectors in concentrated solar power. Renew. Sustain. Energy Rev. 44, 376-390. doi:10.1016/j.rser.2014.12.006

Liang, H., You, S., Zhang, H., 2015. Comparison of different heat transfer models for parabolic trough solar collectors. Appl. Energy 148, 105-114. doi:10.1016/j.apenergy.2015.03.059

López-Grimau, V., Smith, T., Amante, B., Heras, F., 2013. Treatment plant design using natural products for the purification of surface waters in Burkina Faso. Afinidad 70, 93-98.

Moss, T. a, Brosseau, D. a, 2005. Final Test Results for the Schott HCE on a LS-2 Collector 1-22. doi:10.2172/958386

Muñoz, R., Martínez-Val, J.M., Abbas, R., Muñoz-Antón, J., Rovira, A., Montes, M.J., 2015. A Concentrating Solar Power Prototype for validating a new Fresnel-based plant design. Energy Procedia 75, 423-429. doi:10.1016/j.egypro.2015.07.409

National Renewable Energy Laboratory, 2015. NREL.

Nostrand's, V., 2013. Biphenyl and Therphenyls. Sceintific Encycl.

Ouagued, M., Khellaf, A., Loukarfi, L., 2013. Estimation of the temperature, heat gain and heat loss by solar parabolic trough collector under Algerian climate using different thermal oils. Energy Convers. Manag. 75, 191-201. doi:10.1016/j.enconman.2013.06.011

Paris Climate Change Conference, 2015. Paris Climate Change Conference - November 2015.

Peterseim, J.H., Tadros, A., Hellwig, U., White, S., 2014. Increasing the efficiency of parabolic trough plants using thermal oil through external superheating with biomass. Energy Convers. Manag. 77, 784-793. doi:10.1016/j.enconman.2013.10.022

Querol, P., 2012. Single tank thermal storage prototype. SolarPACES Conf.

Roldán, M.I., Valenzuela, L., Zarza, E., 2013. Thermal analysis of solar receiver pipes with superheated steam. Appl. Energy 103, 73-84. doi:10.1016/j.apenergy.2012.10.021

Roldán Serrano, M.I., 2017. Concentrating Solar Thermal Technologies. Springer International Publishing. doi:10.1007/9783-319-45883-0

S. Relloso, E.D., 2009. Experience with molten salts thermal storage in a commercial parabolic trough plant, in: SolarPaces, Conference, Berlin, Germany.

Solar Paces, 2017. International Energy Agency. Energy Techonology Networks.

Vignarooban, K., Xu, X., Arvay, A., Hsu, K., Kannan, A.M., 2015. Heat transfer fluids for concentrating solar power systems - A review. Appl. Energy 146, 383-396. doi:10.1016/j.apenergy.2015.01.125

World Bank, 2014. African Development Fund: Electricity Infrastructure Strengthening and Rural Electrification Project 48633-ET. 